\section{Cinegrafías: Proto-animación en CINEGRAF}

Júlia Barata $^{(1)}$

(1) Júlia Barata (Coimbra, 1981). Vivió en Portugal, Mozambique, Holanda, España y desde 2013 reside en Buenos Aires, Argentina. Es arquitecta de profesión y dibujante. Autora de Gravidez (Musaraña Editora, 2017), 2 road comics (autoedición, 2017), Cotidiano de lujo (autoedición, 2016), 2 historias de amor (autoedición, 2016), Historias del tren (autoedición, 2016), El azar no es mala suerte (con Alejandro Levacov, Musaraña Editora, 2015), As aventuras pós-modernas de Cecília a peixa (autoedición, Barcelona 2009/ Lisboa, 2010). Participó en El volcán (EMR, Musaraña Editora, 2017), Zona de desconforto (2014, Edições Chili com carne, Portugal) y es autora de una de las diez historietas seleccionadas del Concurso Nacional de Historietas con temática LGBTI 2017, cuyo jurado fue Mariela Acevedo, Max Cachimba y Diego Trerotola.

El CINEGRAF es un proyector argentino de los 70's, ideado como juguete para pasar películas de [proto] animación para niños. Se trata de un proyector muy simples y mecánico de dibujos sobre cinta de papel qué funciona con lamparilla común. Los dibujos venían en frames con globos de texto, cual historieta, y se pasaba de viñeta rotando la manivela pasado el tiempo de lectura de cuadro. Seria semejante a la lógica de las diapositivas, en que a cada diapositiva corresponde a una viñeta, a través de un aparato mucho más primitivo. Muchos niños sin televisión habrán descubierto en horas de experimentación lúdica como ver sus historias dibujadas animarse: con muy pocos recursos alguien puede hacer una película en cuestión de minutos. El papel puede ser papel manteco, papel vegetal, cualquier papel semi-traslucido; se cortan tiras que se pueden pegar con cinta scotch entre si para alcanzar la longitud que se quiera; se dibuja, se enrolla y se proyecta la película. ¿Como un juguete tan mágico y lúdico cayó en el olvido?

Empecé estas animaciones en casa de mi amigo músico Pablo Bronzini, que me mostró su CINEGRAF, con lo cual había visto las películas que hacia con su hermano, dibujando músicas de bandas conocidas.

Yo venia hace rato haciendo historietas que exploraban narrativas gráficas continuas sin recurso a la viñeta, con una impresión más cinematográfica, de travelling.

Proyectamos las historias en viñetas que venían con el proyector, mientras Pablo las acompañaba con el piano. Me fascinó el efecto de luz, sombra, imagen y sonido. Percibí que podía aprovechar la cinta para probar lo mismo que venia haciendo con mis historietas y lograr una narrativa continua, proyectando en movimiento constante en lugar de pasar 
frames ritmadamente: solo tenía que verticalizar la secuencia gráfica. Así, allí mismo, empecé a probar en tiras de papel y proyectamos algo con su música. En unos días me estaría comprando mi propio CINEGRAF medio desconchabado por mercado libre.

Me venía interesando explorar las relaciones en aplicaciones de levante, y dibujé pequeñas historias de citas Tinder, en desarrollo gráfico vertical. Pasados un par de meses, hicimos la primera proyección en vivo de esos experimentos, con Pablo al teclado, en el espacio Moebius (noviembre 2018). La proximidad del aparatito con sus ruiditos de papel rotando manualmente, los dibujos proyectados en dialogo con la improvisación musical generaron una intimidad y magia encantadora.

Durante meses seguí dibujando metros de tiras de papel vegetal hasta qué finalicé una película de aprox. 20min que se llamó Tindergraf. Hicimos una proyección en vivo en Casa Florida/ Musaraña (mayo 2019) para un público chico que rodeaba el proyector, mirando la pequeña proyección $(1 \mathrm{~m} \times 1 \mathrm{~m})$ y escuchando la guitarra y piano de Pablo. Todo el proceso fue lúdico y ajeno a la exhibición masiva o cualquier forma de mercantilización, y nos resultó muy gratificante.

Volví a proyectar la película (siempre con la cinta original) en dos eventos en Lisboa (Julio y septiembre 2019) con acompañamiento musical de Fernando Ramalho (aka Berlau). La película contenía globos de texto en castellano por lo que introducimos voces en vivo para actuar y traducir los diálogos al portugués.

El entusiasmo por el formato de animación llevó a querer llevarlo más allá del presencial. De momento estamos trabajando en la edición digital de Tindergraf con música original de Pablo Bronzini + Fernando Ramalho y actuaciones vocales. Se siguieron pequeñas experiencias de animaciones en que se filmó la propia proyección para edición digital con inserción de música y sonidos grabados (un videoclip, pequeñas animaciones). El resultado es un formato de animación HD con carácter rudimental y analógico.

Personalmente, lo analógico sigue siendo mi forma de experimentación gráfica preferencial y el método que propone el Cinegraf me sirve de anfitrión a dos mundos que pruebo de confundir -la historieta y animación. El proceso me es cómodo y intuitivo, casi rápido, sin recurso al tiempo, a la repetición de gestos y know-how de la animación digital, más allá de la inserción de sonido. Me encanta que los limites entre lo estático y lo cinético se mezclen en la percepción.

Un enfoque de mi trabajo es explorar los meandros de la contradicción -en los vínculos humanos, en la sociedad, y creo poder decir que en su ejecución técnica también se reflete, cuando se encuentra el analógico con lo digital, el viejo con lo nuevo, la post-edición cuidada sobre una proyección casera, casi punk. No hay mucho margen para correcciones en el papel vegetal, lo dibujo directo sin boceto sobre la cinta -y esa inmediatez y imprevisibilidad cooperan con la sensación analógica, torpe, que se mantiene en la digitalización, en juego con el formato tecnológico.

La interacción entre la narrativa gráfica y sonora es esencial: la música y el sonido afectan toda la percepción de la historia, redireccionan la lectura, generan una escenografía imaginaria, ambientes, sensorialidades, quiebres, continuidades, como si pudiese dispensar la energía cinética para animar una historieta.

Puede que no haya más sentido de hacerlo qué la cultura del hacer, que la búsqueda de lo lúdico y de lo bello. 
Animaciones en cinegraf: https://vimeo.com/user97971597

Dibujo: https://www.instagram.com/julia_barata/

Música: https://soundcloud.com/pablobronzini

https://soundcloud.com/fernando-ramalho-1
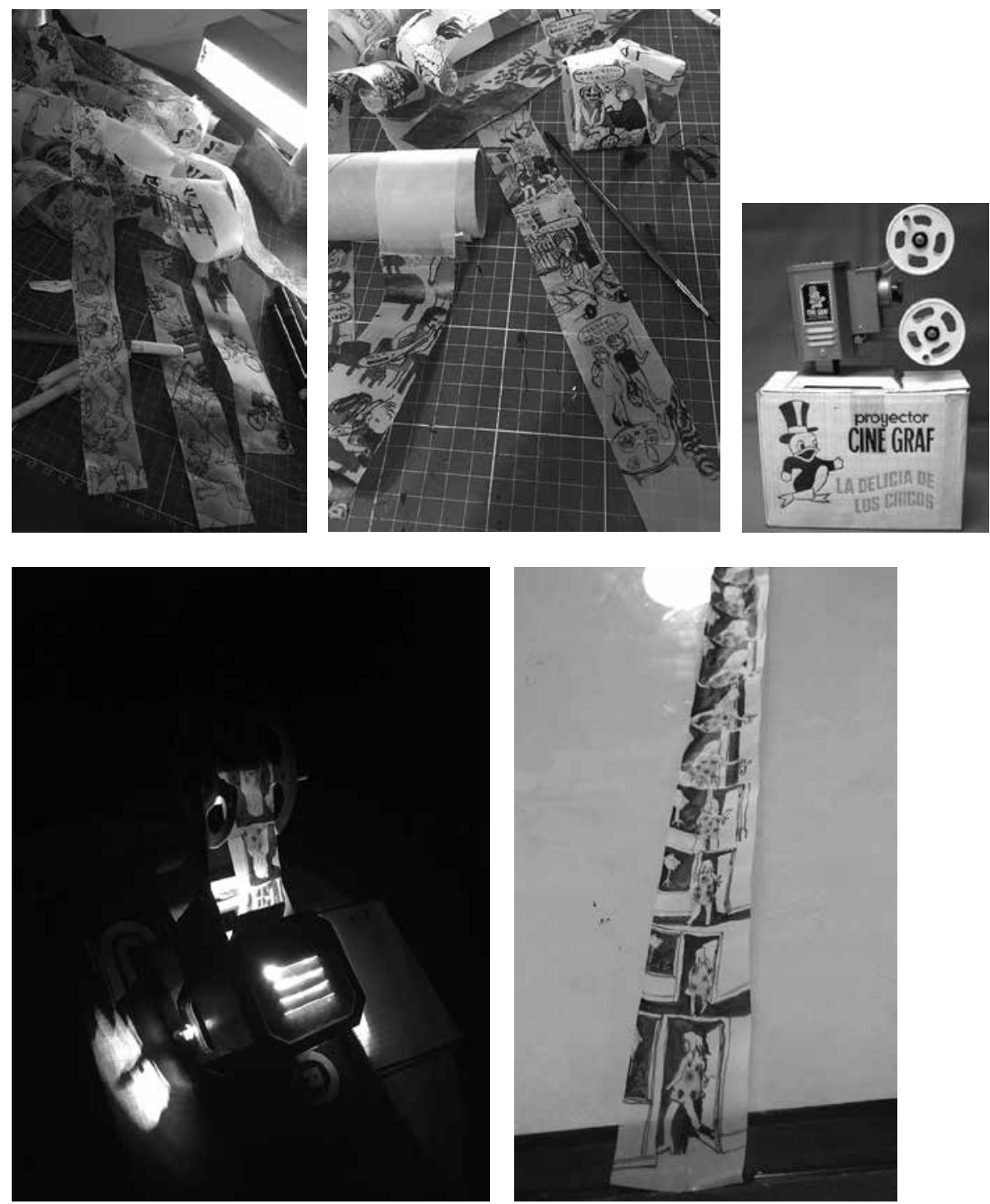